\title{
Prácticas y sentidos sobre el valor político de las fronteras
}

\author{
Political value of the borders: Practices and senses
}

Recibido el 22 de abril de 2019. Aceptado el 16 de diciembre de 2019.

Publicado el 20 de diciembre de 2019.

*Autor para correspondencia: María del Socorro Foio, correo electrónico socorrofoio@gmail.com

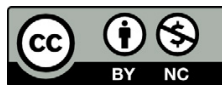

Esta obra está protegida bajo una Licencia Creative Commons Atribución-NoComercial 4.0 Internacional.

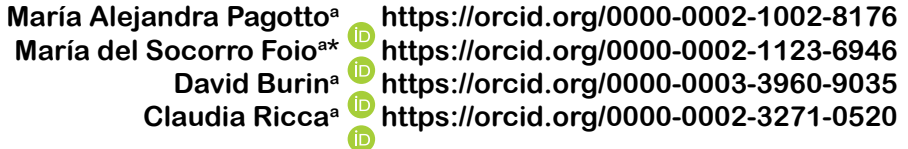

a Instituto para la Inclusión Social y el Desarrollo Humano-Asociación Civil (INCLUIR). Buenos Aires, Argentina, correos electrónicos alejandrapagotto@gmail.com; msfoio@hotmail.com; burundavid@gmail.com; claudiabricca@gmail.com

\section{Resumen:}

En este artículo la noción de frontera es considerada un articulador metodológico y una categoría conceptual. Utilizándola como analizador de zonas de disputa espacial y simbólica, permite indagar tensiones existentes en algunas poblaciones rurales de Argentina y Paraguay que interactúan con espacios, actores y organismos extraterritoriales. Por tal motivo, la categoría de frontera resulta relevante en tanto es considerada una zona históricamente signada por transformaciones e intercambios (tránsito, espacio entre, interpelaciones mutuas) y donde se producen situaciones de violencia, despojo, sometimiento, desigualdad. Ambos procesos instauran demarcaciones y barreras. La tensión principal analizada es en torno al espacio y los sentidos que las poblaciones le atribuyen. Es decir, el derecho a decidir sobre el modo de vida que desean ejercer. Ello ratifica la fertilidad del concepto y constata que ciertas tensiones vigentes se originan en conflictos de larga duración y difícil tramitación por cuanto los sucesos locales están determinados globalmente.

Palabras clave: campo de fuerzas políticas; interpelación de sentidos y prácticas; poblaciones rurales, frontera.

\section{Abstract:}

The notion of frontier in this article is both a means to articulate the methodology and a conceptual category. When used to analyze areas of spatial and symbolic dispute, it allows inquiries into existing tensions among some rural populations in Argentina and Paraguay as they interact with extraterritorial spaces, actors and organisms. Frontier becomes relevant when considered both an area historically-signified by transformations and exchanges (of transit, in-between space and mutual questionings) but also where situations of violence, dispossession, subjugation and inequality take place. Both processes install demarcations and

CÓMO CITAR: Pagotto, M. A., Foio, M. del S., Burin, D. y Ricca, C. (2019). Prácticas y sentidos sobre el valor político de las fronteras. [Political value of the borders: Practices and senses]. Estudios Fronterizos, 20, e040. doi:https://doi.org/10.21670/ref.1919040 
barriers. The main tension analyzed is about space, the significance given to it by populations and their right to decide about the way they want to live their lives. This ratifies the fertility of the concept and makes evident that certain current tensions originate in long-standing conflicts that are difficult to resolve as local events are determined globally.

Keywords: field of political forces; questioning meanings and practices; rural populations, frontier.

\section{Introducción}

La violencia modela la vida y las relaciones que se despliegan en y a través de las fronteras a lo largo del mundo y por ello es una zona privilegiada para visualizar los dispositivos de desposesión y explotación. También, según Mezzadra y Neilson (2017), permite poner de manifiesto los sentidos posibles acerca de lo que se percibe como lo común y como un horizonte de autonomía.

En América Latina, hace ya algunas décadas, existe una literatura que analiza procesos que pueden resignificarse empleando la noción de frontera, entendida como una zona signada por conflictos que incluyen demarcaciones y barreras como así también tránsitos, transformaciones, intercambios, luchas e interpelaciones mutuas. Las prácticas políticas comenzaron a ser consideradas como procesos asociados a la emergencia, expansión y profundización de las luchas sociales, a su organización en torno a nuevos principios identitarios y a la reformulación de los horizontes de liberación o emancipación (Gutiérrez, 2008; 2017).

Para nuestro análisis adherimos a esa perspectiva general ligándola a lo que en este artículo pensamos como frontera. Particularmente, utilizamos la noción de frontera como un articulador teórico y metodológico para la indagación socio-política de disputas en relación al espacio y a los sentidos atribuidos a él por poblaciones rurales en distintas localidades de Argentina y Paraguay.

También nos referimos a las fronteras entre epistemologías, paradigmas y hábitos que orientan la acción de agentes sociopolíticos que actúan en y sobre esos territorios: pequeños productores campesinos, técnicos de agencias estatales, investigadores, funcionarios políticos y empresas. De este modo, consideramos la noción de frontera para a) interpretar acciones referidas a la acumulación y el saqueo en el sistemamundo así como los cambios sociales, económicos y políticos del capitalismo tardío; y b) rastrear formas de la autonomía en disputa ejercida por comunidades rurales de un modo detallado y localizado.

La producción de este artículo se enmarca en un programa de investigación en curso "Aprendizaje de y en auto-gestión. La autonomía como proyecto humano".1 En particular, relacionamos los resultados que ofrece el análisis del presente artículo con uno de los propósitos del programa: la producción de capacidades y prácticas

\footnotetext{
1 Este Programa está radicado en el Instituto para la Inclusión Social y el Desarrollo Humano (Buenos Aires, Argentina) y se desarrolla mediante un convenio de cooperación con la Escuela de Humanidades (Universidad Nacional de San Martín). Parte del programa recibe fondos de la Agencia Nacional de Promoción Científico Tecnológica que financian el Proyecto de investigación "Comprender el aprendizaje colectivo de carácter cooperativo-solidario. Sus pedagogías y dispositivos específicos", dirigido por Ana Heras.
} 
de poblaciones y colectivos sociales que, al tener una orientación hacia la justicia, la libertad y la igualdad como modos de pensar lo social-político frecuentemente interpelan los instituidos de la sociedad.

En su tarea investigativa, este equipo se posiciona a favor de la producción de conocimiento y las intervenciones orientadas a sostener aquellos aprendizajes que, generados colectivamente, promuevan procesos de autoconciencia haciendo que los sujetos sean capaces de reconocer las propias potencias, crear las instituciones para realizarlas e interrogarse sobre el contexto político en tanto se asumen con derechos para ello.

La casuística que presentamos en este artículo fue construida con el objetivo de entender el modo en que estas poblaciones en su cotidianeidad son interpeladas en su derecho a decidir sobre los modos de vida que desean ejercer. En nuestro análisis hacemos visible la frontera como un campo de fuerzas políticas, donde: a) las comunidades interactúan con espacios, actores y organismos extraterritoriales; b) ciertas tensiones vigentes en el territorio se originan en conflictos de larga duración y de difícil tramitación por cuanto los sucesos locales están también determinados globalmente; y c) la acción socio-política del derecho a decidir está vinculada a procesos de violencia, despojo, sometimiento y desigualdad, que el mismo ejercicio de tomar decisiones en algunos casos pone en cuestión e intenta revertir.

El primer caso nos remite a la población de tres comunidades en la zona oriental de Paraguay —Luz Bella, del departamento de San Pedro; Maracaná, del departamento de Canindeyú, y La Pastora, del departamento de Caaguazú- así como de varias comunidades rurales del Pantanal. Se trata de una región campesina donde la agroindustria, liderada por empresas extranjeras y multinacionales, se enfrenta a la producción agrícola familiar, invadiendo sus territorios y expulsando a los pequeños productores. Ante esta situación, las comunidades han desarrollado procesos organizativos tendientes a la protección de los cultivos tradicionales y la soberanía alimentaria. Los datos que dan sustento a este caso se obtuvieron de fuentes primarias; la recolección de los mismos se hizo en el periodo 2008-2014 durante la ejecución de un programa de apoyo a siete comunidades de la región arriba mencionada. La investigadora llevó un cuaderno de campo para registro de las experiencias así como de opiniones fundadas de sus actores. El análisis de estos datos se realizó con un enfoque comprensivo y contextual de las prácticas y sentidos atribuidos de las comunidades.

El segundo caso refiere a la población del Teuco Bermejito, zona rural de la provincia argentina del Chaco. Marcada por la escasez de los servicios educativos, de agua potable y sanitarios, la baja capacidad de subsistencia, la precariedad de las viviendas, la dispersión espacial en veinticuatro parajes separados por grandes distancias e incluso con varios asentamientos familiares en lugares sin acceso vehicular, esta región ha sido caracterizada por sus diferencias étnica y cultural y las históricas disputas entre los pobladores asociadas a esa heterogeneidad. En este caso se trabajó con fuentes secundarias consistentes en un corpus de textos compuesto por estudios sobre el tema (Balazote, 2002; Radovich y Balazote, 2003; Barrios, 2005; Ramos, 2012; Gómez, 2015), el Informe del Proyecto de Desarrollo Integrado Interfluvio Teuco Bermejito, elaborado por el gobierno provincial (рDIтb, 2001), y publicaciones del portal de Amnistía Internacional, del Centro Nelson Mandela y de diarios locales. El periodo considerado en la descripción de las actuales manifestaciones del conflicto abarca desde el año 2000 — con el inicio de la ejecución del proyecto mencionado- al año 2018. El análisis busca desde este enfoque histórico identificar los procesos de conflictos y resistencias en esa población. 
En el tercer caso, la población está constituida por técnicos de programas estatales, funcionarios políticos y pequeños productores y agricultores familiares con quienes trabajan las agencias públicas de desarrollo rural y de la economía popular en Argentina. En el escrito se utilizan datos primarios producidos por entrevistas y notas de registro socio-antropológico (in situ y retrospectivas). La metodología de análisis utilizada presenta el relato de escenas que surgen de la triangulación de entrevistas estructuradas con técnicos extensionistas, decisores políticos y productores, y de la observación de campo en el periodo comprendido entre 2005 y 2017. Se identifican, describen e interpretan las tensiones generadas por las lógicas propias de los distintos actores sustentadas en las particulares condiciones económicas, culturales, profesionales y en modos diversos de pensar y construir relaciones de poder. Así mismo, se elaboran propuestas metodológicas que permiten tender puentes para que las fronteras analizadas puedan ponerse en evidencia y ser cuestionadas a través de dispositivos de investigación-acción en colaboración con los actores involucrados.

El orden de nuestra presentación se corresponde con el desarrollo de una estrategia teórica que procede desde los sucesos singulares hacia la conceptualización. En la próxima sección introducimos una caracterización general de los referentes empíricos. Luego en las tres secciones siguientes realizamos el análisis según la especificidad de cada población y los procesos desarrollados en cada caso. En último lugar presentamos una discusión de lo que, tomado en su conjunto, el material nos permite hacer visible.

\section{Colectivos sociales en situaciones de frontera}

Los investigadores han participado en las experiencias que se analizan ocupando roles específicos de vinculación con los grupos en circunstancias guiadas por propósitos originales muy diferentes, que otorgan singularidad a la producción de los materiales de análisis.

En el caso desarrollado en primer lugar la investigadora se insertó en el marco un proceso de auto-organización campesina durante la presidencia de Fernando Lugo en Paraguay. Según los registros de campo, las organizaciones ambientales y de la sociedad civil se volcaron con entusiasmo a apoyar el proyecto gubernamental de reforma de las relaciones sociales, políticas y económicas. En ese contexto, Sobrevivencia-Amigos de la Tierra Paraguay (organización no gubernamental integrante de la Federación Amigos de la Tierra Internacional, dedicada a la protección socio-ambiental) y Friends of the Earth, England, Wales and Northern Ireland (FOE-EWNI) planificaron un proyecto de apoyo de las comunidades del Oriente paraguayo en su deseo de fortalecer las organizaciones campesinas y sus cultivos tradicionales.

La investigadora produjo los datos que aquí presentamos — reelaborados a los efectos analíticos de este escrito- mientras formaba parte del equipo de planificación y ejecución del proyecto para satisfacer las necesidades de informar sobre los resultados a las comunidades locales, las organizaciones que gestionaban el proyecto y donantes que lo financiaron.

En el segundo caso, el interés se centraba en pensar una estrategia de desarrollo a partir de políticas públicas con los pueblos originarios qom del Chaco argentino. Para 
ello, la investigadora involucrada buscó interrogar sobre la efectividad de las políticas asimilacionistas y proponer la vigencia de posiciones favorables al impulso y desarrollo de prácticas interculturales basadas en la admisión de múltiples mundos. Esa discusión se fue fundamentando a partir de evidenciar las enunciaciones y las prácticas que sostienen el sentido socialmente compartido sobre lo que se puede y lo que no se puede hacer en la comunidad.

La serie de casos se completa con varias escenas que propone el investigador para evidenciar las barreras que se presentan entre los distintos actores que intervienen en la ejecución de proyectos de desarrollo rural, y las condiciones de desigualdad que esas barreras -materiales y simbólicas- generan. Estas reflexiones han surgido en el marco de instancias de evaluación y sistematización de programas de asistencia a pequeños productores campesinos o en procesos de aprendizaje colaborativo con técnicos extensionistas rurales, durante los cuales se presentó la necesidad pedagógica y sociopolítica de habilitar, desde su rol de evaluador o de formador, un pensamiento reflexivo que permitiese sistematizar las prácticas de asistencia y extensión, para mejorar dichos procesos.

Los datos se presentan a través de situaciones que pueden leerse como key events (momentos clave) siguiendo a Gumperz (1982), cuyo análisis promueve las formas de abordaje específicas en cada caso, que se presentan al finalizar la descripción de los mismos.

En la exposición evidenciamos dos aspectos que, aunque a primera vista parezcan contradictorios, co-existen en los casos considerados al analizarse desde la perspectiva de fronteras. Por un lado, se visualizan las condiciones que instalan disputas alrededor del concepto como "barrera" infranqueable a favor de despojos de tierras, culturas y saberes. Como contrapartida, presentamos una reafirmación de la noción de frontera en los procesos sociopolíticos como territorialización de luchas por espacios materiales y simbólicos, entendidas en términos de enunciaciones en disenso y en prácticas organizativas que enfrentan las desigualdades.

Asimismo, a nivel epistemológico, la idea de frontera implicaría su concepción como lugares-entre conocimientos disciplinados, lenguas, geografías, instituciones, lo que conlleva poder pensarnos y actuar como investigadores no amarrados a jerarquías organizacionales y de saberes ni a límites irreducibles entre elaboración teórica, investigación y acción política.

\section{Disputas en la frontera campesina paraguaya}

Entre 1883 y 1885, después de la Guerra de la Triple Alianza (1865-1870), se dictaron en Paraguay leyes de ventas de tierras públicas que en cinco años enajenaron 25 millones de hectáreas de las poco más de 30 millones que tenía el país. En 2008, el $85 \%$ de la tierra estaba en manos del $2 \%$ de la población, situación que constituye una de las mayores desigualdades de la tenencia de la tierra en el mundo (Rojas, 2017).

En ese año FOE-EWNi y Sobrevivencia comenzaron a trabajar con las comunidades de Luz Bella, Maracaná y La Pastora en torno a tres componentes:

a) Enfoque de derechos socio-ambientales. Se capacitó a los miembros de las comunidades desde una perspectiva de derechos: a vivir en ambientes saludables, a tener acceso a agua potable, a que los bosques no sean 
desmontados. Se realizó el seguimiento de denuncias de persecución de líderes campesinos y acompañó a los miembros de las organizaciones campesinas en sus reuniones con autoridades locales y nacionales;

b) Fortalecimiento de la agroecología. La capacitación en la producción en las fincas, chacras y huertas ayudó a afianzar los conocimientos sobre cómo mejorar la producción y comercialización de sus productos;

c) Desarrollo de programas socio-ambientales para radios comunitarias. Se capacitó a los miembros de las comunidades en la producción de mensajes agroecológicos y en aspectos técnicos del establecimiento y gestión de una radio comunitaria.

El proyecto se expandió en 2011 a siete comunidades de Oriente y Pantanal, finalizando sus actividades en 2014. La propuesta y los contenidos de las capacitaciones fueron desarrollados en asambleas abiertas y participativas. El proyecto se complementó con un eje de trabajo de cabildeo en Asunción, el Reino Unido y Bruselas, donde los productos de las capacitaciones, las denuncias y las demandas de las organizaciones campesinas constituyeron insumos para campañas y presentaciones ante los parlamentos europeo y británico.

La evaluación del proyecto fue realizada por un especialista en gobierno local y organizaciones de la sociedad civil, con experiencia en el contexto paraguayo. Los datos obtenidos permiten afirmar que se produjo un fortalecimiento de los territorios y las organizaciones campesinas así como efectos esperados e inesperados para cada situación.

En 2007 comenzaron en La Pastora, municipio de diecisiete comunidades campesinas, las disputas por las plantaciones de soja y durante 2008 los actuales habitantes estuvieron cinco meses en las calles organizados para frenar exitosamente la entrada de camiones sojeros al territorio municipal.

Algunos de los líderes históricos de esa resistencia habían sido referentes de las Ligas Agrarias Cristianas, primer gran movimiento campesino paraguayo en los años ' 60 que ya no existe como tal. Las luchas en La Pastora son similares a las que reivindicaban las Ligas Agrarias: reforma agraria, propiedad comunitaria de la tierra, organización campesina, soberanía alimentaria, redes solidarias de comercio, entre otras.

Durante una visita del presidente Lugo a Caaguazú en 2008, la organización campesina Coordinadora Distrital por la Defensa del Medio Ambiente en La Pastora estuvo al frente del pedido de implementación de un Plan de Ordenamiento Territorial (РОт) que no permitiera la plantación de transgénicos en sus territorios. ${ }^{2}$

A solicitud de la Coordinadora, Sobrevivencia llevó a cabo capacitaciones entre los habitantes para apoyar el desarrollo del рот que se aprobó en 2012.

Luz Bella se formó cuando en 1973 dos grupos de campesinos de Coronel Oviedo y San Pedro que eran perseguidos políticos, se asentaron en tierras a la orilla del río Jejui. A fines de los años '80 se vendieron tierras fiscales a militares, brasileños y otros extranjeros. La comisión vecinal, creada en esa época, hizo un pedido de

\footnotetext{
${ }^{2}$ La Coordinadora es una organización auto-convocada que reivindica la agro-ecología, la tenencia de la tierra a manos de las familias productoras y el ordenamiento territorial para promover alternativas al modelo agro-exportador extractivista. Tiene propuestas políticas y de comercialización colectiva de la producción, reconociendo que se necesita llegar al gobierno municipal para gestionar el territorio y generalmente esto implica mejorar las alianzas con ONG y organizaciones sociales para el asesoramiento jurídico, electoral y productivo; obtener recursos financieros para las campañas electorales; forjar alianzas electorales a nivel comunitario y reforzar la organización de las bases.
} 
expropiación al Parlamento y en 1998 reclamó y obtuvo 963 hectáreas. En 2000 se formó la Asociación Campesina de Productores Alternativos y Ecológicos (ACPAE-LB), reemplazando a la comisión vecinal. En 2001 se estableció la escuela básica secundaria y en 2006 la Iniciación Profesional Agropecuaria. Las líneas estratégicas diseñadas por ACPAE-LB incluían el establecimiento de un colegio agro-técnico, un puesto de salud, una radio, un parque y centro comunitario, más un proyecto de viviendas. En 2011, como una iniciativa de ACPAE-LB y con la asistencia técnica de Sobrevivencia, se abrió el bachillerato técnico en ciencias ambientales. A pesar de no contar con apoyo político municipal, se desarrolló en 2014 una propuesta de ordenanza para declarar a Luz Bella como comunidad agroecológica. Entre 2016 y 2017 se estaban construyendo más de 70 casas en el barrio Eco-Urbanístico gracias a subsidios estatales gestionados por ACPAE-LB.

En 2014, al finalizar el proyecto, entre los efectos esperados observamos que las comunidades habían adquirido la capacidad para preparar una propuesta propia de gestión autónoma y sustentable de sus territorios, incluyendo planes para las elecciones municipales, desarrollo del turismo rural, formación de líderes campesinos en las escuelas técnicas agroecológicos, mejora de oportunidades de ventas a través de nuevas cooperativas y alianzas y el desarrollo de planes de ordenamiento territorial en otras áreas. En muchos casos, las radios comunitarias y las redes sociales se habían convertido en canales de denuncia y registro de casos, democratizando el proceso de seguimiento y demanda de resolución. Luz Bella y varias comunidades en Pantanal fueron particularmente activas en utilizar los medios masivos de comunicación para sus denuncias, convirtiéndose en referentes de provisión de información sobre la realidad campesina a nivel nacional. Se realizaron encuentros de líderes comunitarios de distintos distritos para crear propuestas de trabajo conjunto, no solo en la producción y comercialización de los productos de la agroecología sino también en sus deseos de acceder a cargos representativos de toma de decisiones a nivel local. El apoyo a las escuelas técnicas agroecológicas habilitó que los jóvenes iniciaran estudios universitarios en áreas que les permitieran continuar defendiendo sus territorios y reforzar vínculos con las organizaciones comunitarias. Miembros de organizaciones campesinas tuvieron la oportunidad de intercambiar experiencias de lucha por sus territorios, desafiando el aislamiento. En esos encuentros, y en toda asamblea que cada organización mantenía en sus comunidades, se propiciaba la posibilidad de pensar y crear juntos una forma diferente de sostener la vida que la impuesta por el modelo productivo avasallador. Esos conocimientos se construyeron y reforzaron en la actividad colectiva: en las denuncias contra las fumigaciones, en cada programa de las radios comunitarias donde se compartían recetas de medicinas caseras; en las ferias de productos de las fincas agroecológicas, y en las prácticas de campo en las escuelas agro-técnicas.

Estas iniciativas auto-gestionadas requieren, no obstante las transformaciones que se han ido generando, de políticas públicas que apoyen la tenencia de la tierra y la matriz de producción agropecuaria propuesta por las asociaciones, dando prioridad a la producción campesina, familiar, agroecológica y haciendo una verdadera distribución de la riqueza en todo el territorio.

Permanentes reivindicaciones del modo de vida campesino que va desapareciendo bajo un mar verde de soja transgénica ayudan a blindar a las comunidades de los 
atropellos de los brasiguayos $^{3}$ y de las fuerzas de seguridad paraguaya que a menudo los protegen.

Una de las modalidades utilizadas por los sojeros es comprar los lotes de familias que no pertenecen a las organizaciones de productores agro-ecológicos, fragmentando las topografías locales, creando "huecos" donde se filtra la frontera sojera y aparentemente dejando desamparados a los campesinos. La respuesta campesina es denunciar las plantaciones de soja en las comunidades ante las autoridades locales y con sus socios urbanos, regionales e internacionales, con distinto éxito en cuanto a poder detener su avance. Al interior de cada comunidad existe una multiplicidad de alineamientos con o en contra de los productores sojeros, las políticas gubernamentales, el uso de agrotóxicos, entre otros; los que podrían dar cuenta de la movilidad de las fronteras de pensamiento y acción.

Para contrarrestar las acciones que provocan el despojo de las comunidades, el proyecto de Sobrevivencia/FOE-EWNi promovió el fortalecimiento de las interacciones hacia la solidaridad; por ejemplo, capacitaciones en el uso de la radio comunitaria para difundir información sobre el modelo de producción agro-ecológica y la visita de autoridades nacionales y del Embajador del Reino Unido a las comunidades. La articulación entre esas estrategias crea puentes regionales e internacionales que acercan a "vecinos ideológicos" (Heras y Miano, 2017) a prácticas defensoras de modos de vida anti-hegemónicos, contestatarios del modelo agroexportador.

En el caso de la visita del Embajador, fue la presión del socio europeo del proyecto en el Reino Unido lo que logró que un socio comercial del gobierno paraguayo pudiera interesarse en la situación del campesinado. Sin embargo, esto representaría una alianza táctica en una coyuntura específica - y no un caso de vecindad ideológicaya que en América Latina las embajadas de países como el Reino Unido y los Estados Unidos cumplen funciones de solidificación de estrategias de neo-colonización (promoviendo industrias altamente extractivas como la minería a cielo abierto) en sentido opuesto al promovido por ACPAE-LB.

Podemos afirmar que las fronteras entre campesinos y sojeros/corporaciones son poseedoras de una doble cualidad de resistencia y permeabilidad: resistencia y blindaje a las interacciones hacia el despojo y apertura a las interacciones hacia la solidaridad. Estas dos interacciones deben darse en conjunto para tener el mayor efecto, como lo evidencian las actividades que continúan llevando a cabo las comunidades, varios años después de haber concluido el proyecto de Sobrevivencia/ FOE-EWNI.

La descripción del caso visibiliza la existencia de una lucha desigual y que se asume en su deseo de transformación, donde en la acción de las comunidades autoorganizadas aparece el lugar de un tercero como facilitador, sostén de la misma. Si bien las organizaciones campesinas con las que se trabajó tienen antecedentes históricos importantes en términos de luchas territoriales, la asunción en 2008 del Presidente Lugo hizo posible que estas reivindicaciones tuvieran un interlocutor en el estado paraguayo por primera vez. En este contexto, la Secretaría de Medio Ambiente (SEAM) apoyó la presencia de las organizaciones internacionales que pudieron ofrecer asistencia técnica y financiamiento en los encuentros y talleres de capacitación que funcionaron como catalizadores para el fortalecimiento de las organizaciones y las comunidades campesinas.

\footnotetext{
${ }^{3}$ Término usado localmente para denominar a productores que pueden haber nacido en Paraguay pero que, generalmente, residen en Brasil.
} 
Una vez que fue depuesto el Presidente Lugo, se perdió el apoyo de la SEAm pero las organizaciones campesinas apostaron a participar en espacios municipales de decisión e injerencia.

Las zonas de frontera, en tanto son articulaciones, pueden verse también como zonas donde existen actores que "están ahí", dando la disputa, pero que son a su vez sostenidos o amenazados por actores que "no están siempre ahî" pero que tienen influencia en lo que allí ocurre; esto está planteado claramente tanto en las reflexiones sobre las prácticas de cogestión como en las referidas a las territorializaciones de los pueblos indígenas.

\section{Territorialidad en disputa en el chaco}

El proceso de poblamiento y construcción de la nación argentina se realizó sobre un territorio en el que habitaban comunidades indígenas, cada una con su cultura, memoria y tradición. En el noroeste de la provincia del Chaco desde fines del siglo xix, simultáneamente con la derrota militar de los pobladores originarios, se desarrollaron colonizaciones irregulares promovidas por familias criollas provenientes de las provincias de Santiago del Estero y Salta. Estas se radicaron en áreas que correspondían a los frentes de avance del ejército, en tierras aptas para ganadería extensiva donde también se asentaban grupos indígenas desplazados de espacios ocupados para la explotación agroforestal.

En momentos en que la estatalidad en la región era precaria se esperaba que los pobladores criollos contribuyeran a forjar un nuevo orden sustentándose en el apoyo gubernamental y en la guarda de la corporación militar, que dio fin a las reyertas provocadas por la intrusión en tierras habitadas por pobladores originarios qom.

Las formas de reproducción social de ambos grupos se tradujeron históricamente en territorialidades superpuestas en pugna por los recursos: mientras que los indígenas usan el monte para mariscar, los criollos realizan una explotación ganadera extensiva en áreas únicamente delimitadas por el tránsito de los animales a campo abierto.

En la década de 1920 como resultado de esas disputas, justificadas simbólicamente por los propios agentes territoriales en la oposición "qom-criollo", se producen enfrentamientos armados. Esos sucesos llevaron al Estado en 1924 a reconocer 150.000 Ha. "exclusivamente destinadas a que se concentren los indios del Norte, que se ven obligados a tener que deambular sin destino" (Decreto año 1924 en Balazote, 2002). Esta sedentarización y disciplinamiento de las familias qom, según Balazote, resultaba funcional a los modelos regionales de explotación maderera y algodonera basados en la incorporación intensiva de mano de obra no calificada.

Durante los siguientes setenta y cinco años transcurridos desde aquel decreto de cesión territorial no se produjeron avances en la regularización de la situación dominial. La lucha del pueblo qom ante la intensificación de la venta de tierras fiscales en zonas lindantes y de autorizaciones de tala de montes llevó al gobierno del Chaco a formalizar en 1999 la escritura de las tierras a favor de la Asociación Comunitaria Meguesoxochi.

Dicha Asociación —que evoca el nombre del último cacique muerto en combate contra el avance militar- había sido creada diez años antes por las comunidades 
indígenas con el objetivo de lograr el reconocimiento de los derechos adquiridos, defender y recuperar sus tierras. El reclamo del título por la comunidad qom -en total 413 familias- impulsó a su vez la constitución de la Comisión de Ganaderos de la Zona del Teuco Bermejito, en el marco de un debate sobre quién era el dueño legítimo de las tierras. El título de propiedad fue entregado a la Asociación con una restricción de uso por cinco años a favor de los criollos que serían relocalizados.

El Estado provincial puso en marcha en la zona el Proyecto de Desarrollo Integrado Teuco-Bermejito — PDITB-, creándose en el marco del mismo una Comisión Mixta compuesta por agentes estatales y representantes de los pobladores locales, con la finalidad de definir alcances, términos de referencia y objetivos del Proyecto.

Según lo establecido por la Comisión, el gobierno se comprometió a reubicar al $80 \%$ de las 425 familias criollas residentes en el territorio. El resto no sería reasentado ya que había gestionado la compra del predio ocupado ante la Dirección Provincial de Colonias. En ese caso para el Estado quienes tuvieron interés en acceder "legalmente" a la tierra no se verían afectados, mientras que las otras familias serían consideradas como "marginales por opción" al no cumplir con la posibilidad de convertirse en propietarios del predio (Barrios, 2005).

A partir de la titularización comunitaria, para las organizaciones qom y los agentes gubernamentales la nueva oposición pasó a ser "propietarios-intrusos".

El traslado provocó en las familias angustia por tener que recomenzar con la actividad productiva e incertidumbre ante el cambio. Al sentimiento de despojo y discriminación y el consiguiente reclamo de los derechos de ocupación se sumará la necesidad de admitir un reposicionamiento social con respecto al indio, a quien consideraba como subordinado.

Con el propósito de evitar tensiones interétnicas y pleitos judiciales, el PDiTв apuntó al mejoramiento de la base económica, la implementación de proyectos productivos, la construcción de consensos sobre pautas de convivencia, el rescate de la memoria colectiva y la afirmación cultural. El área del Proyecto comprendía $214.000 \mathrm{Ha}$. (Área de reserva de usos múltiples); 150.000 de propiedad de la comunidad qom y 64.000 para relocalizar a la población criolla (Barrios, 2005; рDIтв, 2001).

La convocatoria oficial de participación en el Proyecto de los pobladores afectados llevó a los criollos a crear la Asociación F.OR.T.IN cuyo objetivo era el acceso a los recursos naturales y la capacitación para la producción. Si bien sigla resume la denominación "Familias Organizadas por las Tierras del Interfluvio", el empleo de la palabra "fortín" remitía al pasado de choques y disputas territoriales con los indígenas ${ }^{4}$ (Gómez, 2015; Barrios, 2005).

Durante la ejecución del PDITB, los técnicos y funcionarios gubernamentales en sus intervenciones cotidianas desvalorizaron las prácticas de los campesinos criollos a ser relocalizados procurando reconvertirlas según los modos de gestión y trabajo propios de los agricultores chaqueños de ascendencia europea, sin considerar la desigualdad en las condiciones de producción de unos y otros (Barrios, 2005).

Ello fue generando en los criollos una auto-percepción como ciudadanos marginados al considerar que el no reconocimiento por parte de las autoridades de

\footnotetext{
${ }^{4}$ Finalizada la dominación española en el Virreinato del Río de la Plata, los gobiernos patrios realizaron expediciones militares ofensivas — que se conocieron como "campañas al desierto"-, con el establecimiento de atrincheramientos, denominados fortines, con el fin de ir ocupando progresivamente el territorio perteneciente a los pueblos indígenas.
} 
su permanencia ininterrumpida en el Interfluvio - a pesar de las condiciones de vida desfavorables sufridas desde la radicación de sus antecesores- los colocaba casi fuera de las fronteras de la nación (Ramos, 2012; Barrios, 2005; Radovich y Balazote, 2003).

De hecho, a casi veinte años de la entrega del título, los gobiernos sucesivos no han atendido los compromisos con las familias que debían relocalizarse. Durante ese tiempo se producen acusaciones de organizaciones qom dando cuenta de la existencia de conflictos con pobladores criollos por la permanencia de 300 familias no reubicadas o que retornaron a las tierras comunitarias al no haber obtenido condiciones para desarrollar sus actividades en otros predios fiscales de acuerdo a lo estipulado en el PDITB.

El distanciamiento de las comisiones directivas de las asociaciones Meguesoxochi y F.OR.T.IN llevó a que sus líderes no estén comunicados para defender el territorio de usurpaciones y extracciones no autorizadas e hizo que dejen de ser un contrapeso para exigir al Estado el cumplimiento de las leyes de protección y conservación de los bienes naturales, así como los traslados y compensaciones de la población criolla (Ramos, 2012).

En un contexto de agudización de los procesos de pauperización de la región, la disputa territorial ha sido caracterizada como una guerra entre pobres.

En años recientes distintas denuncias realizadas por familias criollas a través de la Asociación Campesina Río Teuco perteneciente al Frente Nacional Campesino, y por grupos qom opositores a las autoridades de la Asociación Meguesoxochi por considerar que la misma tiene afinidad con el gobierno provincial- han dado cuenta de la existencia de acuerdos de los dirigentes qom con funcionarios estatales y empresarios forestales, vinculados con la tala ilegal del monte para venta de madera alegando que ello atenta contra la naturaleza a la vez que perjudica la actividad de los propietarios de las tierras comunitarias (indígenas), en un caso, o de los ocupantes (criollos), en otro caso.

Paralelamente, la Asociación Comunitaria ha protestado y accionado penalmente contra los pobladores criollos que realizan desmontes en sus chacras para uso del suelo en cultivos agrícolas. ${ }^{5}$

El veto del poder ejecutivo a la ley que impulsaba la prohibición de explotar los montes de las propiedades comunitarias indígenas durante cuatro años para permitir su regeneración natural y recuperar sustentabilidad ambiental y social (Ley provincial 7.775), llevó a profundizar el reclamo de los denunciantes por considerar que esa situación beneficia los intereses económicos de los explotadores forestales a la vez que incrementa la disputa entre los criollos e indígenas que residen en las tierras de la Asociación Meguesoxochi.

Ante la persistencia del conflicto, una de las respuestas del gobierno fue la de concertar con la Asociación una metodología que asegure su participación formal en la gestión de las solicitudes de permisos para la explotación de actividades en la zona entendiendo que de esa manera se consideran tanto las necesidades de los pobladores qom quienes pueden vender la madera con la correspondiente guía forestal, como

\footnotetext{
${ }^{5}$ Amnistía Internacional, Recuperado de http://territorioindigena.com.ar/ Casos?id_conflicto=110 (6 de septiembre de 2018); Diario Norte de Resistencia, 15 de enero y 16 de junio de 2014; Centro Nelson Mandela, Resistencia, 24 de mayo de 2016.
} 
las de los campesinos criollos asegurando la no aprobación de permisos en las áreas donde estos residen. ${ }^{6}$

Otra respuesta gubernamental, destinada en este caso a crear fuentes de trabajo, ha sido el Convenio de Cooperación Mutua y Asistencia firmado con la Asociación en 2017 para impulsar y coordinar el Programa de Desarrollo Turístico de El Impenetrable (Master Plan) cuyo objetivo es generar actividad económica y oportunidades para el aprovechamiento sustentable del patrimonio natural y cultural de la región. ${ }^{7}$ El proceso de titularización comunitaria produjo nuevas formas de expresión a las tensiones históricas generadas en la competencia por el espacio y por el sentido que se le daba a este - en los colonos criollos como un recurso a apropiarse, en las comunidades qom como un espacio natural a respetar y del cual el ser humano es parte- poniendo de manifiesto un juego de oposiciones que tiende a reforzar las diferencias culturales en referencia a una adscripción étnica. En el discurso de los pobladores criollos, la radicación de sus mayores logró transformar un espacio vacío, culturalmente atrasado y económicamente improductivo mediante el trabajo que modifica la naturaleza sustancialmente distinto a la caza, pesca y recolección-. Las actividades ganaderas que estos pobladores realizan se presentan y valoran socialmente como prácticas vinculadas con la esencia nacional-gauchesca, diferenciada de las culturas indígenas y las propias de los inmigrantes europeos.

En el pueblo qom la concepción de la naturaleza como unidad viva reivindica un pensar, sentir y actuar centrado en el equilibrio de la vida de todos los seres que habitan el territorio. Las prácticas de caza, pesca y recolección y el cultivo en pequeñas chacras significan el uso armónico de los bienes naturales, mientras que la ganadería representa en ellos una causa de degradación ambiental (Ramos, 2012; Barrios, 2005; Radovich y Balazote, 2003).

El caso descripto nos remite a un espacio en movimiento donde el choque pasado y presente- de lógicas, temporalidades y racionalidades incompatibles podrá o no admitir la posibilidad de construir un futuro de convergencias de tiempos largos y duraderos que permitan fortalecer procesos de organización, inclusión social y autodeterminación apoyados en la supresión de la desigualdad.

Escobar (2014) formula el planteo de la cultura como diferencia radical basada en la admisión de múltiples mundos, un pluriverso, que implica una perspectiva del territorio definido como el espacio — biofísico y epistémico al mismo tiempo-donde la vida enactuando en base a una ontología relacional, se hace mundo. Se trata de mundos que se co-producen y afectan sobre la base de ensambles parciales que no los agota en su interrelación.

De aquí surge el interrogante sobre cómo diseñar encuentros entre mundos.

Entendemos, en tal sentido, que abordar las relaciones entre culturas considerando la interculturalidad requiere la emergencia de prácticas vinculadas con el diálogo, el asomarse a los bordes de los vínculos entre pueblos, comunidades y grupos sociales, que dan cuenta del aprendizaje de nuevas formas de interrelación (Semorile, 2009; Vera, 2001). Esa adopción de estrategias que preserven y fomenten el pluriverso hará posible generar dispositivos de activación política de la relacionalidad (Escobar, 2014; Borsani, 2011).

\footnotetext{
${ }^{6}$ Centro Nelson Mandela, Resistencia, 24 de mayo de 2016.

${ }^{7}$ Diario Chaco, 13 de junio de 2017; Chaco Día por Día, 7 de abril de 2018.
} 
Pensar en tal posibilidad para la situación analizada, deja abierta una expectativa acerca de nuevos diseños en la política territorial que sean respetuosos de los derechos de los pueblos y de los no humanos. Solo hace veinticinco años que la legislación argentina, a partir de la reforma de la constitución nacional de 1994, admite la existencia de derechos colectivos del nuevo sujeto denominado Pueblo Indígena.

Unida a la reparación de injusticias para el pueblo qom, la política territorial deberá promover procesos de redistribución —de bienes materiales, culturales y de la capacidad de decisión sobre los propios destinos- que permitan que cada cultura pueda llevar a cabo los planes de vida específicos desde su afiliación singular (Díaz y Alonso, 2004; Gómez y Hadad, 2007; Ortiz, 2012).

\section{Fronteras dialógicas en políticas de desarrollo rural}

Para el último caso se revisan las lógicas diversas en tensión puestas en evidencia en la interacción de técnicos de programas y proyectos de desarrollo rural estatales, funcionarios políticos, investigadores del sistema de ciencia y tecnología y pequeños productores rurales -o agricultores familiares- con quienes estos interactúan. Para ello se presentan escenas elaboradas a partir de la triangulación de entrevistas con dichos actores o la observación en terreno, que habilitan la reflexión y, a partir de esta, la formulación de propuestas metodológicas para superar esas fronteras entre saberes.

Escena 1: Como parte de la evaluación de un programa de desarrollo rural se acompañó a un extensionista durante su visita a los productores. En un momento el técnico comenta: "Yo traigo a mi hijo a veces, para que vea lo mal que viven los productores. Así entiende que tiene que estudiar para no terminar como ellos." La efectividad de su trabajo era relativa; se quejaba porque a pesar de repetir varias veces las presentaciones en powerpoint, los productores no aplicaban sus enseñanzas. Las relaciones estaban marcadas por la distancia emocional: daba charlas, proyectaba sus filminas pero no parecía estar comprometido con lo que sucediera con "esa gente". Lo hacía porque era su trabajo y percibía una remuneración. Utilizaba métodos educativos bancarios (Freire, 1972) para exponer temas técnicos, dejando en claro que él era quien tenía el saber pero casi no realizaba prácticas. ${ }^{8}$ Los productores lo respetaban; en definitiva era veterinario, había logrado un título universitario. Además traía las vacunas. Pero no confiaban en su saber técnico. "Qué va a saber el ingeniero... viene un ratito, mira, opina, pero no pone el cuerpo, nunca lo vimos durante una parición, viene demasiado empilchado ${ }^{9}$ para ensuciarse".

Escena 2: En el marco de una sistematización de la experiencia de una organización de productores minifundistas en el noroeste argentino, un productor nos dice: "Para recibir los créditos teníamos que ser pobres, usaban unos criterios para ver si uno encajaba o no como pobre para el Programa. Una de las cosas en que se fijaban era si había baño con descarga de agua o letrina. Yo tenía un baño recién puesto, me había

\footnotetext{
${ }^{8}$ La educación bancaria — término introducido por Paulo Freire - concibe el proceso educativo desde el supuesto de que el educador "deposita" contenidos en la mente del estudiante. En lugar de pensar la educación como un proceso de comunicación consciente y con discernimiento, los métodos bancarios caracterizan al educando como un sujeto pasivo e ignorante que aprende mediante memorización y repetición de contenidos seleccionados e impartidos por un educador poseedor de verdades únicas e indiscutibles.

${ }^{9}$ En Argentina, modismo que significa bien vestido, con elegancia y esmero.
} 
costado bastante comprar los artefactos e instalarlo. Pero lo tiré abajo antes de que vinieran a inspeccionar. Cuando me dieron el crédito, lo volví a construir." Fronteras entre ser pobre y no serlo. Fronteras impuestas por una mentalidad tecnocrática que debe definir —unidireccionalmente-, el modo de focalizar las políticas públicas de una única manera, considerada objetiva. Y de ese modo construir el concepto de pobreza. El límite mismo fuerza y construye pobreza como condición para recibir recursos del Estado. No se trataba de un productor capitalizado, su economía era de subsistencia, pero se había esforzado y había construido un baño con descarga de agua. La casa tenía piso de tierra, techo de paja, no tenía puertas. ¿Ese tipo de construcción era indicador de pobreza o la forma cultural apropiada del lugar para responder a necesidades de protección y cobijo? Estos "techos simbólicos" suelen actuar en la subjetividad de muchos beneficiarios de forma regresiva. En esta escena el productor lee la situación desde un punto de vista estratégico. Debe calzarse la definición de pobre — según el Manual Operativo del Programa— para poder acceder a los recursos y superar la frontera que le imponen, como un modo de mejorar su situación.

En otros casos estos techos simbólicos operan como límite. Ocurre por ejemplo con muchos de quienes están inscriptos en el monotributo social. Realizan un aporte mínimo en concepto de contribuciones para contar con una obra social, pero es el Estado el que cubre el aporte previsional y de este modo pueden facturar hasta un límite anual que, dividido por doce meses del año, mensualmente no llega a alcanzar un salario mínimo vital y móvil. ${ }^{10}$ Si superan ese límite, para poder seguir facturando están obligados a inscribirse en la categoría más baja del monotributo debiendo pagar cuatro veces más aportes para así poder facturar por mes una cifra superior. De aumentar la facturación tienen que volver a subir de categoría, pero en ese caso el incremento de los aportes entre categorías va reduciéndose progresivamente a medida que más se factura. El incremento inicial para pagar el cuádruple actúa como límite. Quienes están inscriptos como monotributistas sociales tienen una frontera interna: deben facturar menos que el salario mínimo por mes. La normativa, si bien posibilita formalizar las ventas, funciona como un freno a la posibilidad de crecer, ser más productivos, ampliar las ventas. Facturar más se percibe como un salto al vacío, un viaje sin retorno. La posibilidad de perder el beneficio impositivo tiene un peso simbólico abrumador. Desalienta cualquier idea o impulso. Una vez encuadrado como "vulnerable social", "mejor no moverse de esa categoría, por las dudas. "Quizás te quitan la Asignación Universal por Hijo, ${ }^{11}$ vaya uno a saber...". Para mantenerse en esa categoría no se puede poseer más de un inmueble, o tener más de tres motocicletas, o más de un auto con una antigüedad mayor a tres años (y otro registrado a nombre del emprendimiento), etc. Fronteras puestas desde el Estado e incorporadas a la psique individual.

Escena 3: Un investigador en ciencias agrónomas experimentaba hacía tiempo con una especie similar al aloe vera que crecía más rápido y tenía mayor resistencia a algunas plagas. Necesitaba realizar un tipo de pruebas que requería su cultivo extensivo, por lo que entusiasmó a un grupo de productores para que lo cultivasen.

\footnotetext{
${ }^{10}$ Resolución conjunta 4263/2010, 9/2010 y 2880/10 Secretaría de Coordinación y Monitoreo Institucional, Secretaría de Desarrollo Rural y Agricultura Familiar y Administración Federal de Ingresos Públicos.

${ }^{11}$ Seguro social de Argentina que otorga a las personas desocupadas, que trabajan de manera informal o precarizada, o que tienen ingresos menores a salario mínimo, vital y móvil, un beneficio por cada hijo/a menor de 18 años o hijo/a discapacitado/a.
} 
Finalmente decidieron sembrar varias hectáreas dando por supuesto que esta otra especie conservaba las propiedades del aloe vera y podía reemplazarla. Al momento de cosechar surgió el problema: no había mercado para esta planta ya que carecía de los principios activos de la original y no poseía otro componente que pudiera ser utilizado en la industria. Los agricultores no lograron vender su producción y de este modo perdieron un ciclo productivo. Sintieron impotencia por no haber imaginado que el científico no iba a tener en cuenta que ellos debían generar ingresos para subsistir.

Escena 4: Un técnico con muchos años de trayectoria trabajaba con varias organizaciones que cultivan bananas y mangos y vendían a precios más competitivos que la fruta importada debido a los menores costos de transporte por la cercanía de los mercados. Con la participación de los productores el técnico formuló proyectos adecuados a las necesidades de cada organización, con montos diferentes según cada una de ellas. Al poco tiempo cambió la gestión gubernamental, designándose a cargo del área a un dirigente partidario sin conocimientos sobre producción rural. Al analizar la cartera de subsidios y créditos preparada por el técnico afirmó que era un error político distribuir de esa forma el dinero y decidió dividirlo en partes iguales, y ampliar la cantidad de organizaciones a subsidiar. El supuesto era que de este modo había más organizaciones relacionadas con su gestión, y al momento de la devolución del dinero prestado, podía facilitar las condiciones de la misma a cambio de apoyos electorales.

La decisión unilateral y autoritaria del funcionario — sin consulta al técnicogeneró discusiones ya que algunas organizaciones no llegaban a contar con el dinero requerido para las inversiones a realizar, mientras que otras se encontraban con una oferta superior a la que podían absorber. No aceptar implicaba enemistarse con el nuevo funcionario, y quizás dejar de recibir la asistencia técnica, Aceptar requería repensar los usos del dinero, ya que no alcanzaba para lo previsto, no garantizaba la sostenibilidad de los proyectos a encarar y eso mismo dificultaba la devolución de los préstamos. Algunas organizaciones entraron en crisis y se disgregaron.

Escena 5: Los técnicos reciben el mandato de la conducción central del organismo al que pertenecen de poner en marcha un programa de subsidios para organizaciones de productores. Para poder implementarlo y ejecutar el presupuesto es necesario constituir organizaciones donde no las haya, por lo cual proponen a varios grupos de productores que venían reuniéndose, conociéndose y trabajando juntos de forma incipiente constituir una figura jurídica que pueda recibir los subsidios. Ese era el objetivo de los técnicos, pero... ¿cuál era el objetivo de los productores? Estos no estaban preparados para sostener una figura legal, no tenían voluntad de reunirse en asamblea, llevar actas, hacer balances, administrar las ventas del conjunto. Tampoco se justificaba económicamente hacer mucho más esfuerzo ya que las familias tenían ingresos extra prediales y parte de lo poco que producían era para autoconsumo. Pero además... tener que definir cargos directivos según la exigencia del estatuto tipo podía generar conflictos en el grupo, dado que hasta el momento se manejaban sin diferenciaciones ni jerarquías. La exigencia de tramitar la personería jurídica y llevar adelante la gestión resultaba excesiva. Parecía mejor estrategia centrarse en el fortalecimiento de los vínculos y en mejorar los aspectos comerciales para ampliar las ventas, que tener que invertir horas de tiempo y energía en hacer trámites, certificar firmas, escribir actas, y ocupar las reuniones en temas burocráticos y formales, en lugar 
de usar el tiempo para aprender e intercambiar sobre aspectos técnico-productivos. Para no enfrentar a los técnicos, los productores finalmente formalizan la organización. El subsidio demora más de un año en concretarse. A esa altura los participantes se habían dispersado.

$\mathrm{Al}$ recorrer los distintos territorios es posible encontrar asociaciones y cooperativas creadas a partir del impulso de técnicos y políticos como requisito para acceder a subsidios y créditos, una lógica instrumental que luego se contrasta con la realidad, ya que, si se parte de este enfoque, no son muchos los casos en los que el grupo se fortalece y la organización sigue unida luego de recibir el subsidio.

El abuso de esta perspectiva construye una significación imaginaria social del asociativismo que lo vincula a una necesidad instrumental: recibir fondos del Estado partiendo de suponer que la mera inversión en bienes materiales puede aglutinar a un colectivo, y así le quita otros sentidos posibles, como el de construir un proyecto a largo plazo con autonomía de las políticas públicas coyunturales basado en lazos solidarios. Por el contrario, hemos presenciado procesos basados en esta otra lógica de la autogestión que siguen aglutinados aun cuando el Estado no les ha financiado proyectos, precisamente por su grado de autonomía.

El trabajo analítico sobre las escenas que presentamos permite mostrar cómo se erigen y actúan fronteras emocionales, pedagógicas, epistemológicas, metodológicas, políticas y económicas que obturan la capacidad de desarrollar un pensamiento autónomo, de comprender y respetar otros modos de organizar la vida y de fortalecer los procesos de autogestión. Cada actor se abroquela en sus intereses y hábitos, sus prejuicios, prescripciones y paradigmas, sin cuestionarse qué otras experiencias existenciales pueden ampliar el modo de ver y operar sobre la realidad.

Las escenas descriptas llevan entonces a preguntarnos ¿Cómo (con qué prácticas, en qué interacciones y dispositivos) es posible atravesar esas fronteras? ¿Cómo producir cambios y aprendizajes sobre otros modos organizacionales posibles y las formas de orientar la acción técnico-política? ¿Qué dispositivos institucionales colectivos y colaborativos es posible construir?

La experiencia que hemos venido desarrollando desde nuestro centro de investigación y en conjunto con otros grupos afines, nos plantea que es posible tender puentes para poner en evidencia las fronteras y analizarlas críticamente a través de diferentes técnicas y dispositivos de investigación-acción en colaboración con los actores territoriales (Heras, 2014). Entre estos podemos destacar:

- La aplicación y adaptación de técnicas de teatro foro, teatro legislativo y otras variantes de teatro del oprimido, que permiten dramatizar situaciones de opresión y pensar los cambios necesarios para superarlas.

- Laedición de fragmentos de entrevistasfilmadas-yuxtaponiendoincongruencias y posturas disímiles- y su proyección a los distintos actores reunidos para discutir luego entre ellos el contenido contradictorio de lo visto.

- La proyección de testimonios de los actores con mayor poder a los actores más débiles, para luego problematizar sobre el contenido de sus discursos explícitos o compararlos con las vivencias y experiencias que tienen los actores más débiles como resultado de las acciones de aquellos con mayor poder.

- La utilización de enfoques provenientes del análisis y la psicología institucional, orientados a hacer explícitos los implícitos y dispositivos que sostienen relaciones de poder asimétricas en espacios inter-actorales al generar diferencias y desigualdades simbólicas. 
- La sistematización de experiencias generadas en un territorio en video para su utilización en otros contextos, sea para mostrar que determinada orientación es posible, como para generar identificaciones o cuestionamientos sobre la experiencia compartida de forma tal de poder identificar aspectos que presentan potencias a desarrollar en lo local.

- La sistematización de legislación orientada a reducir barreras de acceso a los mercados, o que facilita el acceso a recursos como la tierra, el agua o el financiamiento o a mejorar las condiciones de los agricultores familiares, generada en otras geografías, que permiten incidir en la deliberación y aprobación de sistemas legales equivalentes en el nivel local.

- La identificación, descripción y difusión de tecnologías y dispositivos organizacionales innovadores desarrollados por las mismas organizaciones de productores.

- La promoción y acompañamiento de mesas de trabajo en las que participan integrantes o representantes de diversas organizaciones auto-gestionadas para compartir preguntas de investigación. Esto permite el análisis de situaciones críticas con otros identificados como pares, que han vivido o pueden entender ese tipo de situaciones.

- La promoción y acompañamiento de mesas locales de articulación entre técnicos de distintas dependencias gubernamentales y no gubernamentales, regidas por criterios de paridad (más allá de que los técnicos que las integran estén insertos en estructuras jerárquico-burocráticas).

- La traducción a un lenguaje popular de normas e instrumentos para facilitar el acceso de los productores a los recursos (planes de negocios, planillas para la formulación de proyectos, estatutos tipo, etc.).

- El desarrollo de estrategias discursivas e interaccionales para "detonar la burocracia” y facilitar la concreción de proyectos legítimos que suelen no encajar en las pautas previstas en los programas gubernamentales.

\section{Discusión y conclusiones}

El argumento sostenido en el artículo transita un tejido socio-histórico latinoamericano comprendido en un periodo desde el año 2000 hasta la actualidad. A lo largo de la presentación de los casos identificamos diversos modos de producir fronteras y disputas entre las culturas institucionales, las culturas propias de las comunidades rurales, campesinas e indígenas, los organismos internacionales y las lógicas, orientaciones (intereses) y marcos de pensamiento de los actores que intervienen en la formulación y la ejecución de planes y programas de desarrollo en diferentes territorios. Creemos que hacer visibles las fronteras reales y simbólicas, en particular aquellas que generan disparidades y relaciones de poder asimétricas, y diseñar instrumentos conceptuales para analizarlas y, de ser posible, transformarlas, es algo indispensable para el fortalecimiento de las organizaciones autogestionadas de comunidades locales, tanto de productores rurales como de trabajadores urbanos.

La reflexión presentada en este artículo se convierte en un aporte para el quehacer científico en tanto indica un camino a seguir para que el conocimiento generado por distintos actores sociales se construya en forma sinérgica, se articule más allá de las 
fronteras que cada uno transita diariamente y organice un posible modo de entender la ciencia como trabajo.

En términos de nuestro marco teórico, el análisis del primer caso permite reiterar la necesidad de pensar las fronteras entre campesinos que practican una agricultura tradicional y el modelo capitalista agroindustrial-exportador como una moneda de dos caras: por un lado se deben revelar los intercambios que enmascaran más desigualdad y exclusión y, por el otro, descubrir posibles emergencias de fronteras permeables a la creación de vínculos solidarios, que refuerzan la elección de vida de las comunidades campesinas como protectoras del ambiente y proveedoras de alimentos sanos y accesibles.

A su vez, el caso de la zona del Teuco-Bermejito —uno de los tantos territorios indígenas condenados por la modernidad a ser y existir en otro espacio y tiempo diferente-, nos lleva a retomar la dimensión de frontera construida tanto por acuerdos como por tensiones socioculturales, en un choque de mundos disímiles que manifiesta el conflicto en torno a la perseverancia de territorialidades no reductibles a la lógica del capital e instalado como resistencia, desafío y posibilidad de permeación contra la consolidación de un territorio de dominación.

Por su parte, las observaciones realizadas en el tercer caso recalcan nuestra idea de que en la planificación ejecución y evaluación de las políticas públicas de desarrollo e inclusión es preciso desvelar las fronteras establecidas en las formas de pensar de los distintos actores, de pensarse y pensar a los otros, en la imposibilidad o no de tender puentes, y de atravesar fronteras al ponerse en el lugar del otro.

El marco teórico general sobre la noción de frontera en los dos primeros presentados ofrece una variación en su significación. Desde la referencia a las demarcaciones requeridas por las políticas de expansión y conquista: orden-desorden, bordes abiertos-muros de contención y, más específicamente, en el concepto de frontera cultural aludiendo a enunciados y prácticas que sostienen lo que se puede y lo que no se puede hacer, socialmente hablando, cuya expresión más actual se encuentra en la tensión asimilación-pluralismo, se transita hacia ideas relacionadas con procesos de territorialización y re-territorialización y de permeación. Mientras en el tercer caso, la noción de frontera da también paso a un pensamiento-entre, propio de la teoría social, que para su configuración apela al conocimiento generado por diferentes disciplinas y actores.

A partir del análisis de los tres casos, podemos concluir que una diversidad de factores incide de modo tal que tendemos a calificar la experiencia de Paraguay como positiva mientras que las otras dos presentan más dificultades en términos de logros, aunque ofrecen igualmente muchos desafíos para interpelar la noción de frontera. En este sentido, hemos visto que en el primer caso se conjugan diferentes factores que han potenciado la experiencia de resistencia y lucha contra el modelo agro-exportador de despojo que ya venían sosteniendo las comunidades. Ellos son: el empoderamiento del campesinado durante la presidencia de Fernando Lugo, la realización del Proyecto de FOE-EWNi y Sobrevivencia para el fortalecimiento de sus organizaciones y cultivos tradicionales mediante acciones desarrolladas en asambleas abiertas y participativas de capacitación socio-ambiental legal y agro-ecológica y de fortalecimiento de las radios comunitarias y redes sociales que se convirtieron en canales de denuncia y registro de casos, democratizando el proceso de seguimiento y demanda de resolución de los mismos. El conjunto de estas acciones globales mejoró las posibilidades de que los jóvenes permanecieran en sus comunidades y el surgimiento de líderes locales y generó capacidades para preparar propuestas basadas en una gestión autonómica 
y sustentable de los territorios y su soberanía alimentaria. Así mismo, se favoreció la creación de vínculos de resistencia entre las comunidades del proyecto y el intercambio de experiencias de reivindicación territorial y, como herramienta política, la ejecución del Plan de Ordenamiento Territorial permitió implementar frenos contra la entrada o permanencia de transgénicos y agro-tóxicos.

En el caso del Teuco Bermejito el Estado se limitó a restituir parte de las tierras reclamadas. Esta situación, en el contexto socioeconómico actual, ha generado pérdidas para ambos grupos que comparten el territorio dificultando la posibilidad de re(construir), o reterritorializar, la convivencia de mundos múltiples. Las luchas de las comunidades qom en esa zona implican reivindicaciones de los territorios, el autogobierno, el respeto a los sistemas socioculturales propios y una mayor participación en las instancias de generación de políticas y toma de decisiones. Podríamos decir que la apelación a la diversidad cultural que predomina en la política pública llevada a cabo no logra proporcionar respuestas efectivas a las desigualdades a la inserción de sus pobladores en un sistema económico, social, político y cultural hegemónico y globalizado. El establecimiento de fronteras simbólico-semióticas en las situaciones de interacción no se debe únicamente a la existencia de representaciones del mundo distintas por parte de criollos y qom: esas diferencias están signadas por relaciones de poder que no son puestas a la luz y cuestionadas con vista a posibles transformaciones.

En el tercer caso, en lo referente a las políticas de desarrollo e inclusión social consideramos que la mayor parte de las fronteras que aparecen en la implementación de las mismas se establecen en las cabezas de quienes interactúan de manera directa en el territorio: técnicos, productores, funcionarios políticos. Las prácticas de estos actores no son universales. En cada territorio los contextos son específicos, y los sujetos son otros. Esta diversidad de lógicas se acrecienta con la intervención de más actores en otros espacios y tiempos: los responsables de determinar criterios de focalización para fijar los límites para definir la pobreza, o la situación de vulnerabilidad, o de dictar reglamentaciones y regulaciones imposibles de cumplir, difíciles de comprender o que condicionan de manera no consciente la subjetividad de los destinatarios de las políticas públicas.

En síntesis, el recorrido por las experiencias revela dos formas de mirar la frontera: aquella que enfatiza las cuestiones de adentro/afuera, demarcaciones, barreras, y la que refiere más centralmente al tránsito, al espacio entre, al espacio liminal, a zonas interpelables mutuamente; transversalmente visualizamos las relaciones de poder explicitadas en nuestro análisis como disputas. Ese espacio de ir siendo que se construye en una dinámica no determinada y políticamente conflictiva permite asumir otros discursos, otras producciones de sentido, otra semiosis social que será vinculada con una posibilidad de justicia. Nos situamos en el valor político de la frontera, entendiendo que todo posicionamiento es relativo a un campo de fuerzas y por eso las fronteras son a la vez límite y membrana, tope y apertura.

\section{Referencias}

Balazote, A. (2002). Reasentamiento forzoso de población y regularización territorial en el Interfluvio Teuco-Bermejito (Provincia de Chaco). Cuadernos de Antropología Social. Recuperado de http:/ /www.scielo. org.ar/scielo.php? script=sci_arttext \& pid=S1850-275X2002000200003 
Barrios, G. (2005). Armándose de la identidad necesaria. 'Tradiciones' de la población criolla ante la relocalización compulsiva derivada de la devolución de tierras a la comunidad toba-Interfluvio Teuco-Bermejito, Chaco. En J. Rozé y A. Pratesi (Comps.), Conflictos centrales en la periferia de la globalización (178-195). Libros en Red. Recuperado de https://www.insumisos.com/lecturasinsumisas/Conflictos $\% 20 \mathrm{en} \% 20 \mathrm{la} \% 20$ periferia $\% 20 \mathrm{de} \% 20 \mathrm{la} \% 20$ globalaizacion.pdf

Borsani, M. (2011). Anotaciones decoloniales para una relectura de la tensión izquierda-derecha. Revista de Epistemología y Ciencias Humanas, (3). Recuperado de http:/ / www.revistaepistemologi.com.ar/ediciones_anteriores.php?id=4

Díaz, R. y Alonso, G. (2004). Construcción de espacios interculturales. Buenos Aires: Miño y Dávila.

Escobar, A. (2014). Sentipensar con la tierra, Nuevas lecturas sobre desarrollo, territorio y diferencia, Medellín: Ediciones unaula.

Freire, P. (1972). Pedagogía del oprimido. Buenos Aires: Siglo xxi Argentina Editores.

Gómez, C. (2015). Estrategias territoriales y usos políticos de la identidad en el interfluvio Teuco-Bermejito, Chaco. De Prácticas y Discursos. Recuperado de http:// revistas.unne. edu. ar/ index.php/dpd/article/viewFile/808/716

Gómez, C. y Hadad, M. (2007). Territorio e identidad. Reflexiones sobre la construcción de territorialidad en los movimientos sociales latinoamericanos. Actas $4^{\circ}$ Jornadas de Jóvenes. Recuperado de http://jornadasjovenesiigg.sociales.uba.ar/ wp-content/uploads/sites/107/2015/04/HADAD_Gisela.pdf

Gumperz, J. (1982). Discourse strategies. Nueva York: Cambridge University Press.

Gutiérrez, R. (2008). Los ritmos del Pachakuti. Movilización y levantamiento popular-indígena en Bolivia (2000-2005). Buenos Aires: Tinta Limón.

Gutiérrez, R. (2017). Horizontes comunitarios-populares. Producción de lo común más allá de las políticas estado-céntricas. Madrid: Traficantes de Sueños.

Heras, A. I. (2014). Lógica colaborativa y generación de conocimiento colectivo. Alcances y tensiones en la relaciones investigación-sociedad. Población $\mathcal{E}$ Sociedad, $21,137-150$.

Heras, A. I. y Miano, A. (2017). Educación, auto-organización y territorio. Revista Mexicana de Investigación Educativa, XXII, 533-564.

Mezzadra, S. y Neilson, B. (2017). La frontera como método. O la multiplicación del trabajo, Madrid: Traficantes de sueños.

Ortiz, P. (2012). Espacio, territorio e interculturalidad. Una aproximación a sus conflictos y resignificaciones desde la Amazonía de Pastaza en la segunda mitad del siglo xx. Quito: Universidad Andina Simón Bolívar, Sede Ecuador.

Programa de Sustentabilidad Ambiental (рDIтв). (2001). Informe final. Secretaría de Planificación y Evaluación de Resultados, Consejo Federal de Inversiones.

Radovich, J. y Balazote, A. (2003). Multiculturalidad y economía: El caso del Interfluvio Teuco-Bermejito. RUNA Archivo para las ciencias del hombre, XXIV(1), 103-122.

Ramos, J. (2012). La incidencia de los conflictos en el acceso y la gestión de los recursos naturales: el caso de dos proyectos de desarrollo rural implementados en el Interfluvio Teuco-Bermejito. Miríada. Recuperado de https://p3.usal.edu.ar/ index.php/miríada/ article/ view/1413/1795

Rojas, L. (2017). La metamorfosis del Paraguay (documental histórico). Asunción, Paraguay: BASE Investigaciones Sociales. 
Semorile, Z. (2009). Interculturalidad, naturaleza, sociedad y territorio en Patagonia. Actas XXVII Congreso de la Asociación Latinoamericana de Sociología. VIII Jornadas de Sociología de la Universidad de Buenos Aires. Asociación Latinoamericana de Sociología. Recuperado de http://cdsa.aacademica.org/000-062/2292

Vera, H. (2001). Cultura e integración. En [autor(es)]. Bases para la agencia internacional del Paraguay. Asunción: Centro Paraguayo de Estudios Internacionales (CEPEI).

María Alejandra Pagotto

Argentina. Magister en Estudios Interdisciplinarios de la Subjetividad por la Universidad de Buenos Aires. Investigadora en el programa "Aprendizaje de y en autogestión. La autonomía como proyecto humano", en el Instituto para la Inclusión Social y el Desarrollo Humano (Incluir), Buenos Aires. Líneas de investigación: territorialidad, poder, resistencia; producción de subjetividad en situación de calle; prácticas de intervención social. Publicación reciente: Heras, A. I., Miano, A. y Pagotto, M. A. (2017). Una apuesta por la vida: Ética y estética en formas colectivo-solidarias. Nómadas, (46), 129-149.

María del Socorro Foio

Argentina. Doctora en Ciencias Cognitivas, unne, Argentina. Investigadora en el proyecto "Comprender el aprendizaje colectivo de carácter cooperativo-solidario; sus pedagogías y dispositivos específicos" en el Instituto para la Inclusión Social y el Desarrollo Humano (INCLuIR), Buenos Aires. Líneas de investigación: gestión organizacional, territorio, políticas públicas, participación ciudadana. Publicación reciente: Foio, M. del S. (2016). Desarrollo de un modelo de observación del sistema social en espacios participativos promovidos por el Estado. Question, (49), 252-270.

David Burin

Argentino. Técnico químico. Escuela Nacional de Educación Técnica O. Krause, Argentina. Investigador en los proyectos: "Aprendizaje y creación en la construcción de proyectos de autonomía y autogestión" "Aprendizaje y percepción de la diferencia en proyectos de autonomía”, en el Instituto para la Inclusión Social y el Desarrollo Humano (INCLUIR), Buenos Aires. Líneas de investigación: comunicación social, desarrollo local, autogestión, trabajo, emprendimientos cooperativos, políticas sociales. Publicación reciente: Miano, M. A., Burin, D. y Heras, A. I. (2016). Tecnología y autogestión en cooperativas de trabajo. De Prácticas y Discursos, 5, 1-33.

Claudia Ricca

Argentina. Magister en Género y Política, Universidad de Londres. Investigadora en el proyecto "Aprendizajes sobre co-gestión en Centros Educativos para la Producción Total. Análisis etnográfico y sociolingüístico de la interacción en procesos educativos multiactorales", en el Instituto para la Inclusión Social y el Desarrollo Humano (INCLUIR), Buenos Aires. Líneas de investigación: memorias populares y artes visuales. Publicación reciente: Ricca, C. y Scolnik, A. (2017). Memoria histórica y autoorganización en Argentina: Enfoques desde las artes visuales para producir narrativas colectivas con grupos de la sociedad civil. Constructive Engagement of Conflict Journal, (4). 